Zagłada Żydów. Studia i Materiały, R. 2021, nr 17

ISSN (print): 1895-247X; eISSN: 2657-3571

DOI: https://doi.org/10.32927/zzsim.898

\title{
Artur Żmijewski
}

\section{Fotografie z Berka}

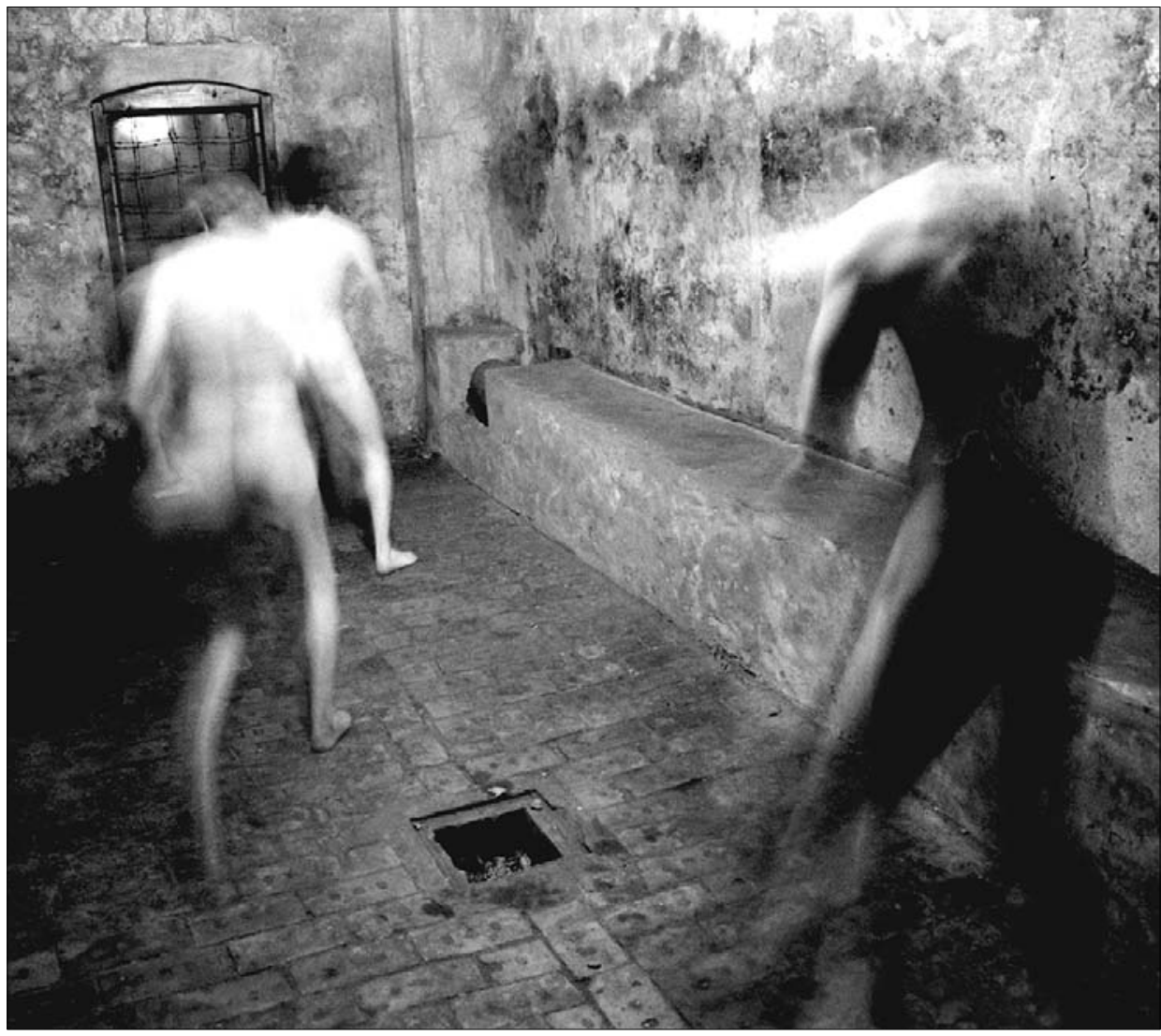




\section{Wokół Berka}
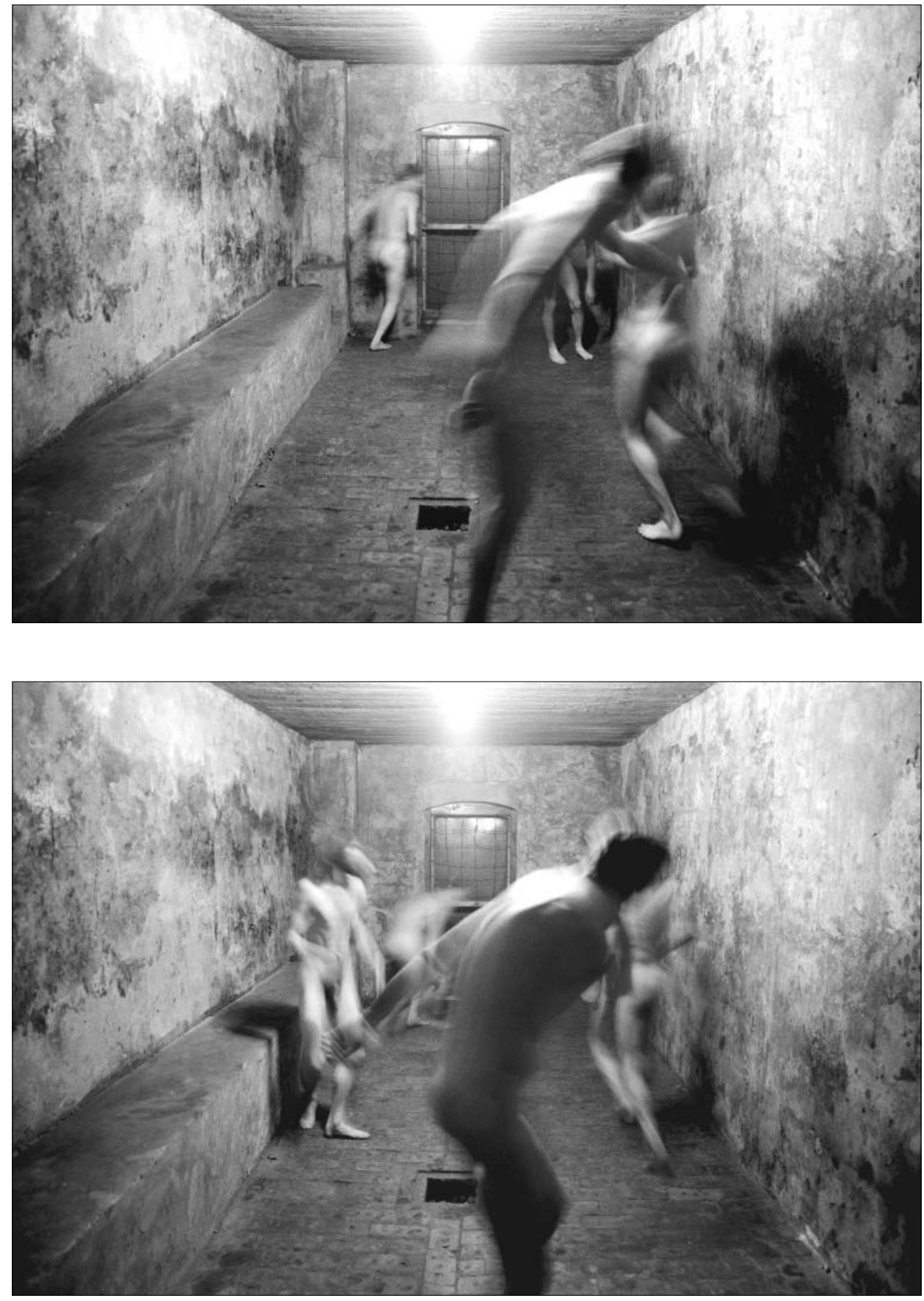

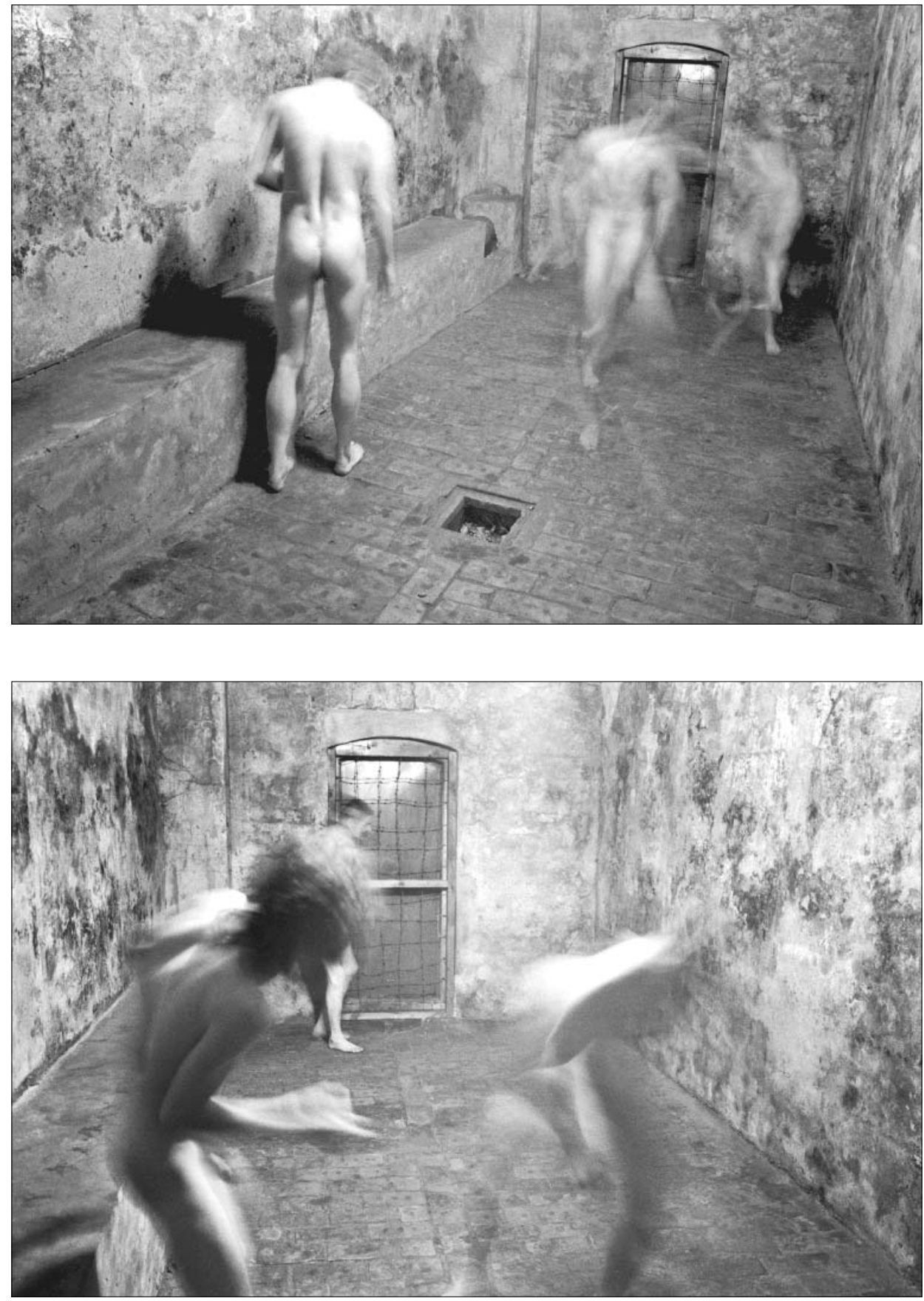


\section{Wokół Berka}
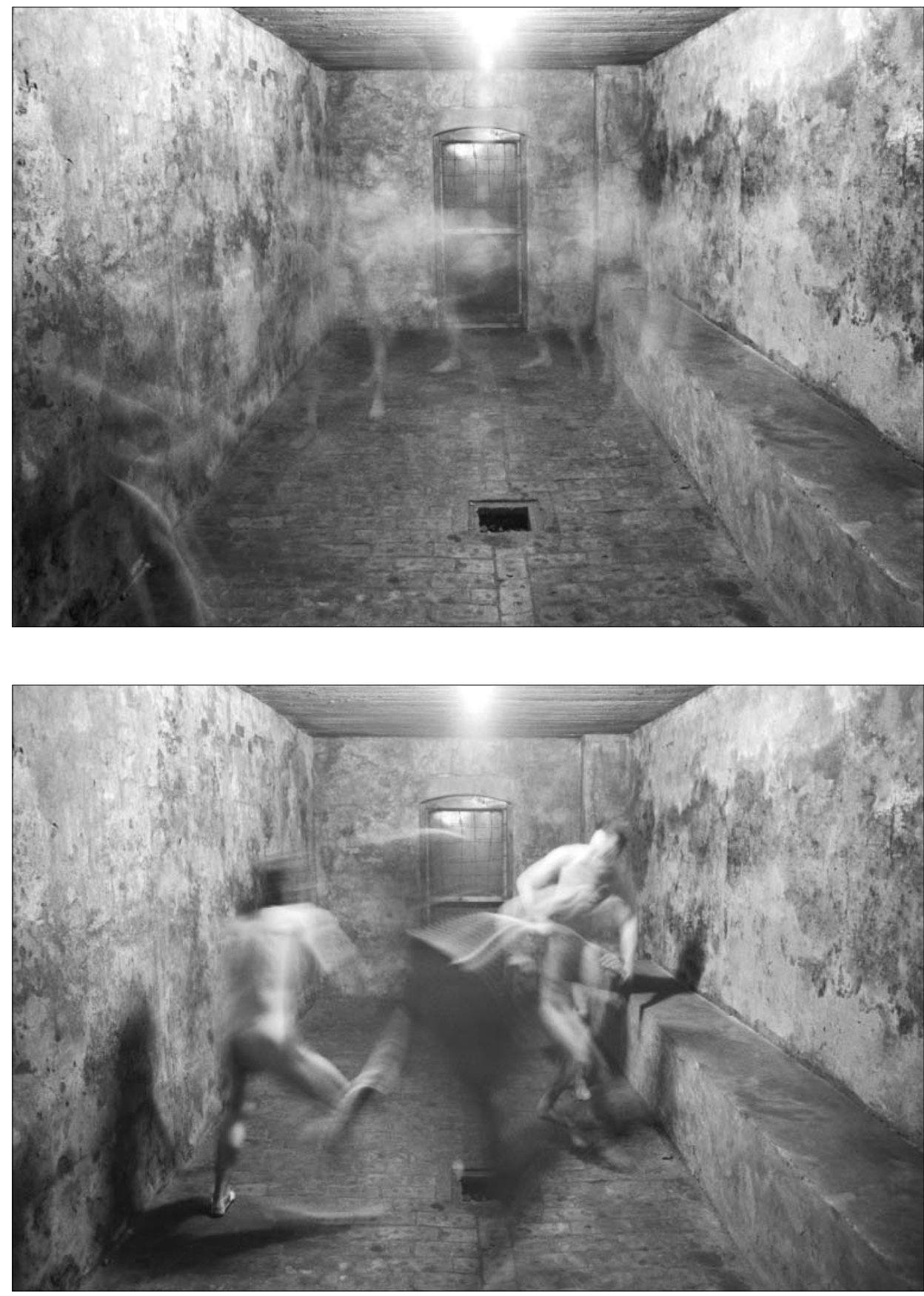

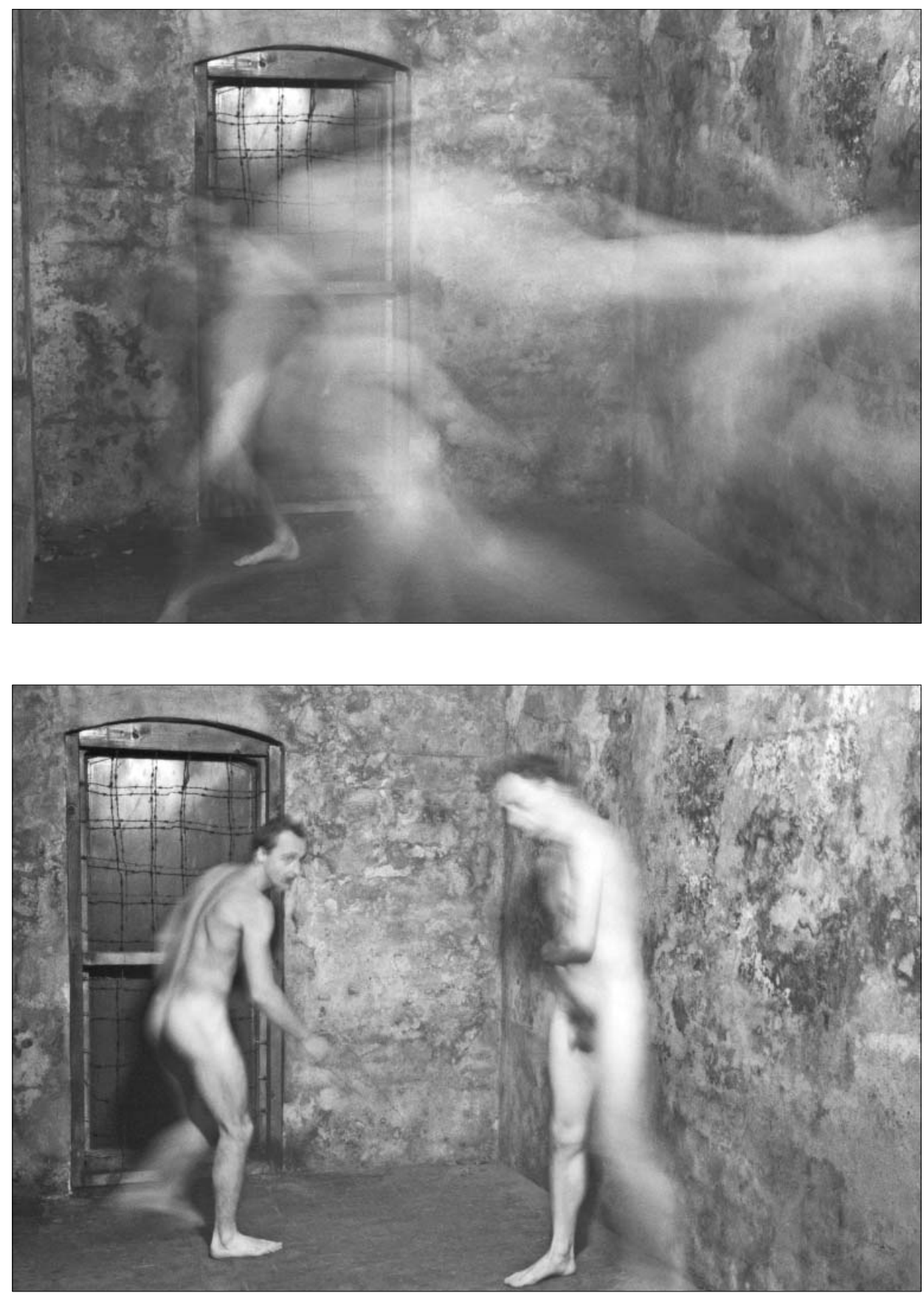


\section{Wokół Berka}
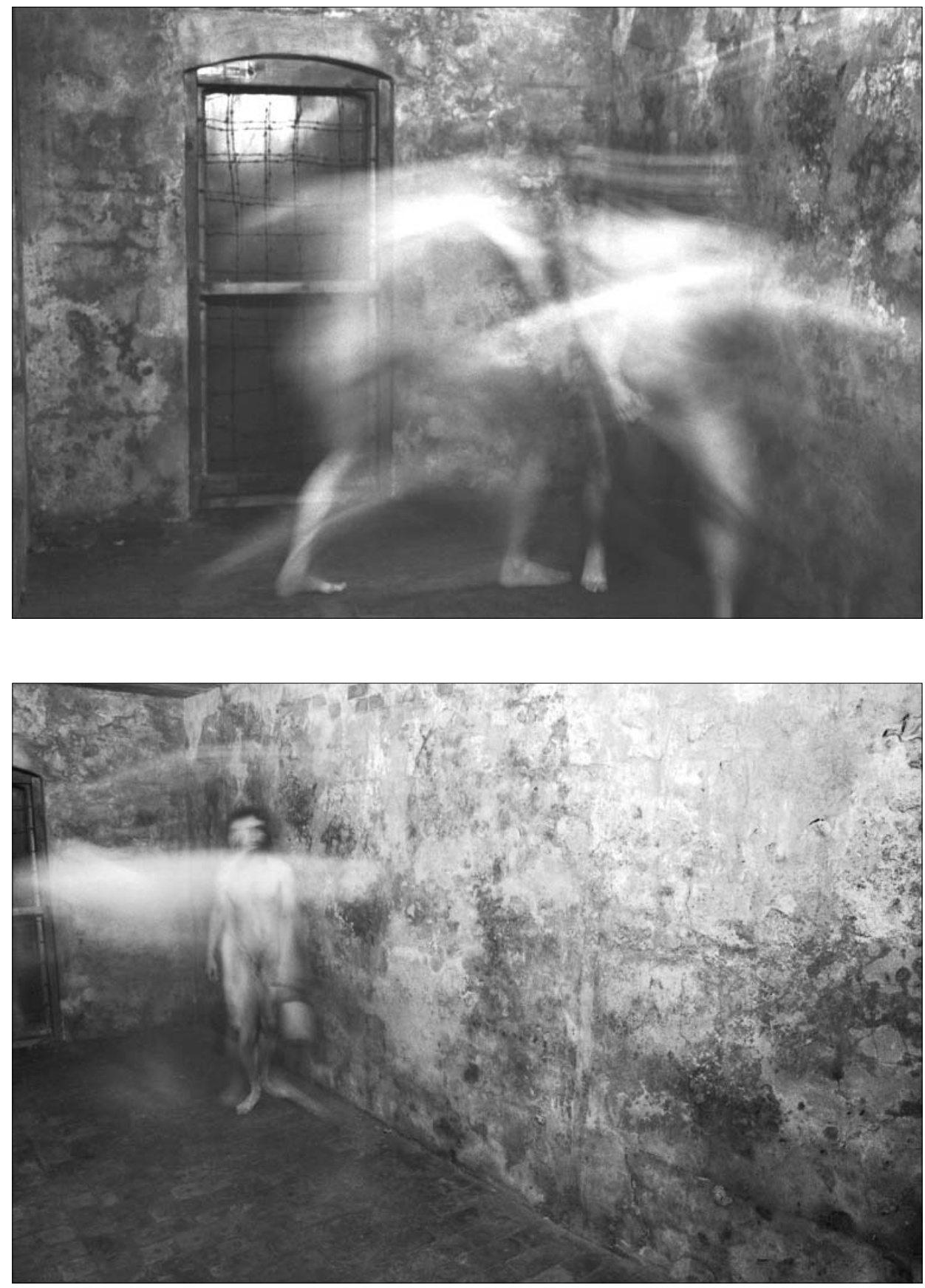

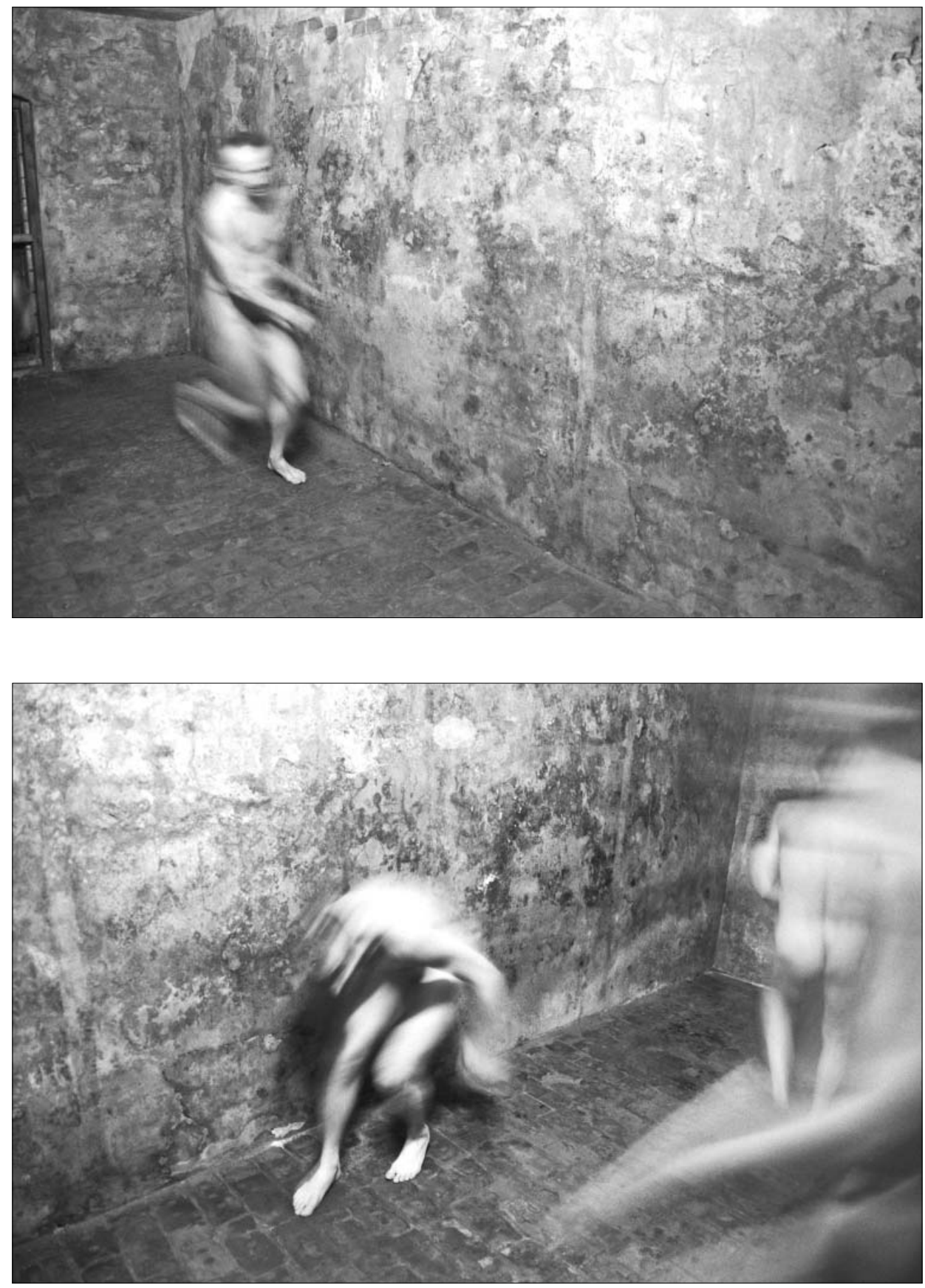


\section{Wokół Berka}
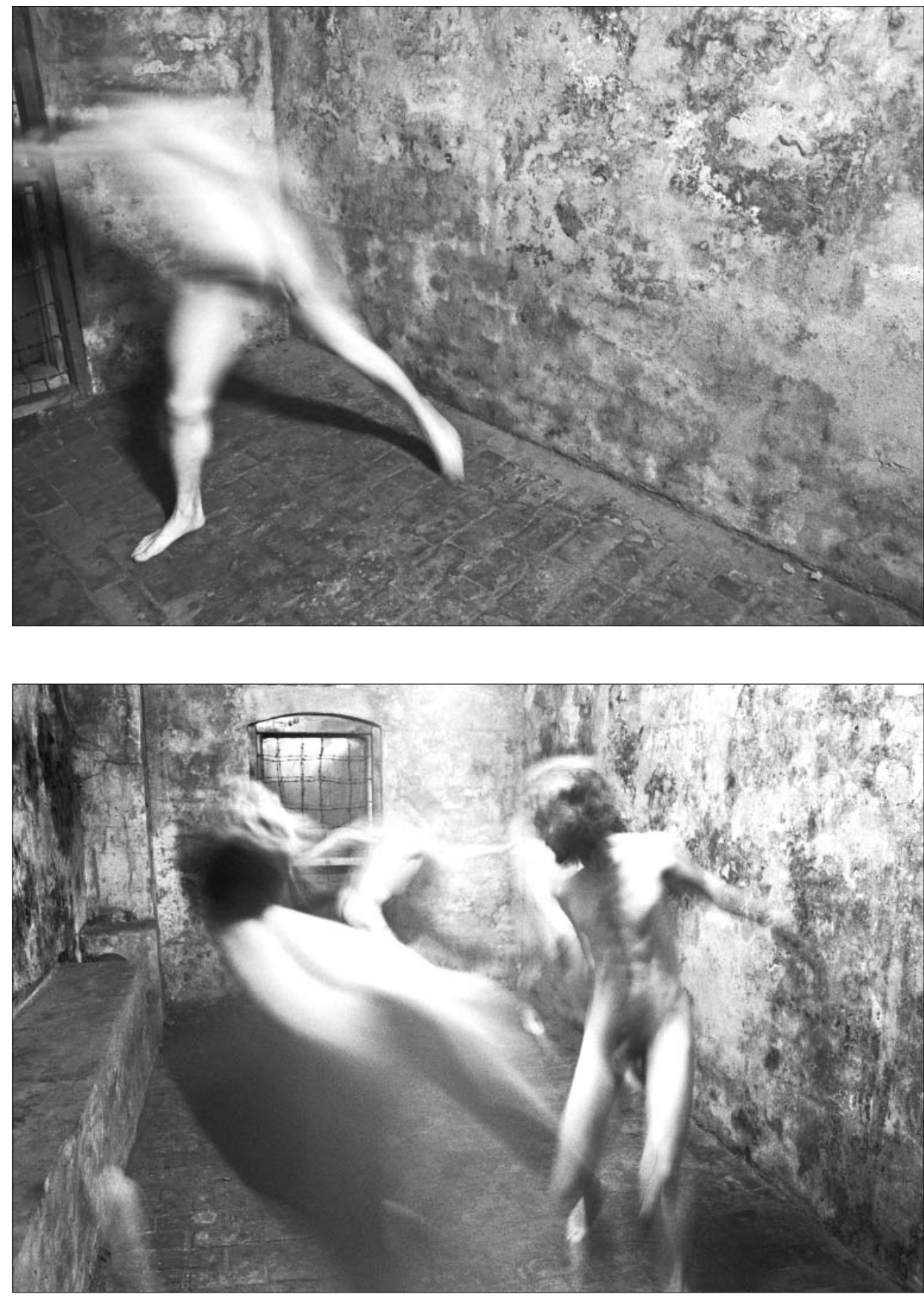